\title{
Understanding the inverse care law: a register and survey-based study of patient deprivation and burnout in general practice
}

\author{
Anette Fischer Pedersen ${ }^{*}$ and Peter Vedsted
}

\begin{abstract}
Introduction: According to the inverse care law, there is a mismatch between patients' medical needs and medical care supply. As an example, the number of doctors is often lower in areas with high deprivation compared to areas with no deprivation, and doctors with a deprived patient population may experience a high work pressure, have insufficient time for comprehensive tasks and be at higher risk for developing burnout. The mechanisms responsible for the inverse care law might be mutually reinforcing, but we know very little about this process. In this study, the association between patient deprivation and burnout in the general practitioners (GPs) was examined.

Methods: Active GPs in the Central Denmark Region were invited to participate in a survey on job satisfaction and burnout and 601 GPs returned the questionnaire (72\%). The Danish Regions provided information about which persons were registered with each practice, and information concerning socioeconomic characteristics for each patient on the list was obtained from Statistics Denmark. A composite deprivation index was also used.

Results: There was significantly more burnout among GPs in the highest quartile of the deprivation index compared to GPs in the lowest quartile (OR: 1.91; 95\% Cl: 1.06-3.44; p-value: 0.032). Among the eight variables included in the deprivation index, a high share of patients on social benefits was most strongly associated with burnout (OR: 2.62; 95\% Cl: 1.45-4.71; p-value: 0.001).

Conclusions: A higher propensity of GP burnout was found among GPs with a high share of deprived patients on their lists compared to GPs with a low share of deprived patients. This applied in particular to patients on social benefits. This indicates that beside lower supply of GPs in deprived areas, people in these areas may also be served by GPs who are in higher risk of burnout and not performing optimally.
\end{abstract}

Keywords: Burnout, General practice, Inverse care law, Medical care supply, Patient deprivation

\section{Introduction}

According to the inverse care law, the availability of medical care tends to vary inversely with the need for it in the population served [1,2]. For instance, in primary care, deprived patients have been shown to have reduced access to scheduled encounters and to spend less time with the general practitioner (GP) during consultations than more affluent patients [3-5]. This is true despite the fact that patients from deprived areas often present with a higher number of problems in the clinical encounter than patients from more affluent areas [3]. Patients from

\footnotetext{
* Correspondence: AFP@feap.dk

Research Unit for General Practice and Research Centre for Cancer Diagnosis in Primary Care (CaP), Health, Aarhus University, Aarhus, Denmark
}

poor areas have been shown to perceive the GP as less patient and less caring than patients from more wealthy areas [6] and a negative correlation between patient deprivation and patient-rated enablement in encounters for psychosocial problems has been reported [3].

These factors reflect double trouble for people in deprived areas as they often have higher levels of physical and mental multimorbidity and problems of psychosocial nature than people in less deprived areas.

Even though GPs tend to be inversely distributed with fewer in deprived areas, the clinical activities have been shown to be higher in deprived areas compared to more affluent [7]. This could mean that GPs working in such areas would be exposed to more stressful conditions that

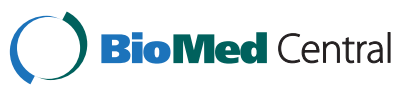


could lead to lower performance and job satisfaction. Eventually, the GP may move from the area or stop practicing contributing to the inverse care law. Although it is universally accepted among GPs and researchers that the work is more stressful in areas of social deprivation [8], the actual association between deprivation and perceived workload is not well-investigated.

Burnout is common among GPs [9] and the problem seems to be increasing [10]. Burnout is a psychological construct defined as a prolonged response to chronic emotional and interpersonal stressors on the job and is characterized by emotional exhaustion, depersonalization and a subjective experience of decreased personal accomplishment [11]. Burnout has been shown to influence doctors' ratings of the quality of their own medical care negatively. Thus, burnout has been associated with self-reported suboptimal patient care practices [12], an increased number of self-reported errors among surgeons and primary care physicians $[13,14]$ and selfreported unprofessional conduct and decreased empathy among medical students $[15,16]$. Thus, the inverse care law may operate in at least three ways: fewer doctors available, less time for appropriate care and impaired doctors due to the effects of increased work pressure.

On this background it is relevant to examine whether GPs working in deprived areas are actually more prone to burnout than GPs working in more affluent areas. We hypothesised that burnout is more frequent among GPs with a high share of disadvantaged patients than among GPs with a low share of disadvantaged patients in the practice population.

The aim of this study was to examine whether burnout in GPs is associated with patients' socioeconomic characteristics.

\section{Methods}

Setting

All GPs in Denmark are independent contractors with the regional health authorities and they are fully responsible for the organization of the work in their practice. This also includes premises and staff. According to the national contract, the practice has to be open from 8 AM until 4 PM, from Monday to Friday. Acute patients should be seen the same day and non-acute patients within five weekdays. Virtually all GPs make use of an appointment scheme with consultations of 10-15 minutes. Approx. $40 \%$ of GPs are solo GPs. The patient list size is on average 1550 patients per GP (including children) and $99 \%$ of citizens are registered with a particular general practice, which they have to consult for medical advice. GPs also act as gatekeepers to the rest of the health care system except for emergencies. GPs are remunerated on a mix of capitation and fee-for-service (25/75\%).

\section{Study population and survey}

In January 2012, all 835 active GPs in the Central Denmark Region (1.2 mill inhabitants) were invited to participate in a survey on job satisfaction, burnout, and working conditions ("the GP profile"). The active GPs were identified by the Registry of Health Providers, which is managed by the Regional health authorities. Non-respondents were sent a reminder after four and thirteen weeks and GPs were remunerated in the amount of $50 €$ for responding. According to Danish law the study was not submitted to an ethical committee since questionnaire surveys do not require an ethical approval. The study was approved by the Danish Data Protection Agency.

\section{Questionnaire and register-based data}

The questionnaire included a burnout scale and items about practice organisation (solo or group practice) and weekly working hours in practice. We used the Maslach Burnout Inventory Human-Services-Survey (MBI-HSS), which is considered to be a valid instrument for assessment of burnout symptoms [17]. The scale has been translated into Danish following standardised procedures. The MBI-HSS consists of 22 items and each item is scored on a 7-point Likert scale. The 22 items are divided on three subscales: 1) emotional exhaustion (9 items), 2) depersonalization (5 items), and 3) personal accomplishment (8 items). Each subscale receives a score which is categorised as low or high based on normative population score [17]. A high level of emotional exhaustion is defined as a score $>26$, and a high level of depersonalization is defined as a score $>9$. Low personal accomplishment is defined as a score $<34$ (reverse score). A moderate degree of burnout is defined as a high score on the emotional exhaustion subscale and/or a high score on the depersonalization subscale. A high score on the emotional exhaustion and depersonalization subscales and a low score on the personal accomplishment subscale is defined as a high degree of burnout [17]. Respondents who did not fulfil criteria for either a severe or moderate degree of burnout were classified as not burned-out.

The Danish Deprivation Index (DADI) was developed for use in general practice [18]. This index takes a value between 10 and 100 and high numbers indicate more deprived patients in the practice population. The index is calculated in accordance with the Jarman index [19] and the variables and their weights are presented in Table 1. The Danish Regions provided information about which persons were registered with each practice and each patient's civil registration number. By means of this number, information concerning socioeconomic characteristics was obtained from Statistics Denmark. The socioeconomic characteristics of the practice population were aggregated as proportions per 100 listed persons. 


\section{Table 1 Variables and weights in the DADI}

\begin{tabular}{ll}
\hline Variable & Weight \\
\hline $\begin{array}{l}\text { Share of 20- to 59-year-old patients, who have been } \\
\text { unemployed for more than } 6 \text { months }\end{array}$ & 0.100 \\
$\begin{array}{l}\text { Share of 20- to 59-year-old patients' education } \\
\text { at high-school level or below }\end{array}$ & 0.125 \\
$\begin{array}{l}\text { Share of 20- to 59-year-old patients with } \\
\text { low disposable income }\end{array}$ & 0.100 \\
$\begin{array}{l}\text { Share of 18- to 59-year-old patients on social benefits } \\
\text { Share of 0- to 16-year-old children in families with low income }\end{array}$ & 0.150 \\
$\begin{array}{l}\text { Share of immigrants and descendants from non-western } \\
\text { countries }\end{array}$ & 0.250 \\
$\begin{array}{l}\text { Share of patients above } 30 \text { years of age living alone } \\
\text { Share of patients above } 70 \text { years of age with a low level } \\
\text { of disposable income }\end{array}$ & 0.075 \\
\begin{tabular}{l} 
Total \\
\hline
\end{tabular} & 0.100 \\
\hline
\end{tabular}

We adjusted for net family income using the Oxford equivalence scale suggested by the organization of economic corporation and development (OECD) [20]. A person's net income was adjusted for household size and composition of adults and children.

The DADI was classified as "low", "medium" or "high" based on the $25^{\text {th }}$ and $75^{\text {th }}$ percentiles: low DADI: $\leq 25^{\text {th }}$ percentile, medium DADI: $>25^{\text {th }}$ to $\leq 75^{\text {th }}$ percentile and high DADI: $>75^{\text {th }}$ percentile.

\section{Analysis}

The difference in mean DADI scores between responding GPs and non-responding GPs was tested with Students unpaired t-test. The scores for burnout were calculated for each responding GP. The associations between burnout and level of DADI and each of the eight DADI variables were calculated as odds ratios (ORs) in separate logistic regression models. We calculated the crude ORs and the adjusted ORs. In the adjusted models, the following potential confounding variables were included: sex and age of GPs and number of consultations during the previous year (2011). As some of the GPs were working in the same practice, the adjusted analyses were corrected for clusters of GPs within the same practice using robust variance estimates. Moreover, analyses were repeated including solo GPs only as a sensitivity test of the results derived from the total population. The 95\% confidence intervals $(95 \% \mathrm{CI})$ for estimates were calculated and p-values of $5 \%$ or less were considered statistically significant. Data was analysed using STATA 12.

\section{Results}

In total, 601 (72.0\%) GPs returned the questionnaire and 592 had completed the MBI. Among these, 153 (25.5\%) reached the criteria for moderate burnout. The characteristics of the study population are shown in Table 2 .
Calculation of DADI was based on 1474 patients per GP on average (median $=1470$, interquartile interval $=1265-$ 1629). The mean DADI for responding and non-responding GPs was $26.3(\mathrm{SD}=7.1)$ and $26.9(\mathrm{SD}=6.4)$, respectively. This difference was non-significant $(t=1.11$; $\mathrm{p}=0.266$ ).

Among GPs with a high DADI, 32.7\% were classified as moderately burned-out compared with $22.9 \%$ of the GPs with a low DADI. The crude and adjusted ORs for burnout was $1.81(95 \% \mathrm{CI}=1.04-3.16, \mathrm{P}=0.037)$ and $1.91(95 \% \mathrm{CI}=1.06-3.44, \mathrm{P}=0.032)$ for GPs with a high DADI (low DADI as reference group), respectively (Table 3). GPs in the middle DADI quartiles did not differ significantly from GPs with a low DADI in their likelihood of burnout.

Among the eight socio-economic variables included in the DADI, the share of 18-59-year old patients on social benefits was the factor most strongly associated with GP burnout with an adjusted OR of 2.62 (95\% CI = 1.45-4.71, $\mathrm{P}=0.001$ ) for the highest quartile compared with the lowest (Table 3). Regarding the share of patients above 30 years of age living alone, GPs in the second and third quartiles had increased risk of burnout compared to GPs in the lowest quartile (adjusted OR for second quartile = $1.91,95 \% \mathrm{CI}=1.02-3.58, \mathrm{P}=0.043$ and adjusted $\mathrm{OR}$ for third quartile $=1.98,95 \% \mathrm{CI}=1.08-3.66, \mathrm{P}=0.028$ ). The higher risk of burnout in GPs in the highest quartile did not reach statistical significance (adjusted $\mathrm{OR}=1.64,95 \%$ $\mathrm{CI}=0.90-3.00, \mathrm{P}=0.108$ ) (Table 3).

The sensitivity analysis including 131 solo GPs showed the same tendency that DADI was linearly associated with GP burnout. However, the association was statistically insignificant. Furthermore, the share of 18-59-year old patients on social benefits was the factor with the strongest association with GP burnout (highest quartile vs. lowest quartile: $\mathrm{OR}=7.19,95 \% \mathrm{CI}: 1.57-32.87, \mathrm{P}=0.011$ ).

\section{Discussion \\ Key findings}

We found that GPs with a practice population in the highest deprivation (DADI) quartile had nearly twice the risk of being classified as burned-out compared to GPs in the lowest DADI quartile. This was true after adjusting for possible confounders such as sex and age of the GP and number of consultations during the previous year. When examining each of the eight variables included in the DADI individually, a higher share of patients on social benefits was strongly associated with risk of GP burnout.

\section{Strengths and weaknesses}

The high response rate and the use of a validated scale for assessment of burnout strengthen the results of the present study. Moreover, unique Danish registries provided 
Table 2 Characteristics of the participating 601 GPs

\begin{tabular}{|c|c|c|c|c|c|c|}
\hline & \multirow{2}{*}{\multicolumn{2}{|c|}{$\begin{array}{l}\text { All GPs } \\
\begin{array}{l}\mathrm{N}=601 \\
(100 \%)\end{array}\end{array}$}} & \multirow{2}{*}{\multicolumn{2}{|c|}{$\begin{array}{l}\text { Burned-out } \\
\text { GPs } \\
\mathrm{N}=153 \\
(25.5 \%)\end{array}$}} & \multirow{2}{*}{\multicolumn{2}{|c|}{$\begin{array}{l}\text { Burnout-free } \\
\text { GPs } \\
N=439 \\
(73.0 \%)\end{array}$}} \\
\hline & & & & & & \\
\hline & $\mathrm{N}$ & $\%$ & $\mathrm{~N}$ & $\%$ & $\mathrm{~N}$ & $\%$ \\
\hline \multicolumn{7}{|l|}{ Sex of GPs } \\
\hline Males & 312 & 51.9 & 77 & 50.3 & 232 & 52.8 \\
\hline Females & 284 & 47.3 & 74 & 48.4 & 204 & 46.5 \\
\hline Missing information & 5 & 0.8 & 2 & 1.3 & 3 & 0.7 \\
\hline \multicolumn{7}{|l|}{ Age of GPs } \\
\hline $34-45$ & 149 & 24.8 & 40 & 26.1 & 107 & 24.4 \\
\hline $46-53$ & 155 & 25.8 & 42 & 27.5 & 108 & 24.6 \\
\hline $54-59$ & 154 & 25.6 & 40 & 26.1 & 113 & 25.7 \\
\hline $60-70$ & 137 & 22.8 & 29 & 19.0 & 107 & 24.4 \\
\hline Missing information & 6 & 1.0 & 2 & 1.3 & 4 & 0.9 \\
\hline
\end{tabular}

Number of consultations during 2011*

$\leq 4363$
$4364-5187$
$5188-6008$
$\geq 6009$

DADI

$\leq 21.5$
$21.6-25.5$
$25.6-30.0$
$\geq 30.1$

Missing information

Share of unemployed patients (20-59 yrs.)

$\begin{array}{lllllll}\leq 1.5 \% & 149 & 24.8 & 29 & 19.0 & 116 & 26.4 \\ 1.6-1.9 \% & 148 & 24.6 & 42 & 27.5 & 104 & 23.7 \\ 2.0-2.4 \% & 151 & 25.1 & 37 & 24.2 & 113 & 25.7 \\ \geq 2.5 \% & 146 & 24.3 & 45 & 29.4 & 99 & 22.6 \\ \text { Missing information } & 7 & 1.2 & 0 & 0.0 & 7 & 1.6\end{array}$

Share of patients with education at high-school level or below (20-59 yrs.)

$\leq 22.6 \%$
$22.7-26.5 \%$
$26.6-29.8 \%$
$\geq 29.9 \%$
Missing information

$$
\begin{array}{llllll}
149 & 24.8 & 37 & 24.2 & 108 & 24.6 \\
149 & 24.8 & 30 & 19.6 & 118 & 26.9 \\
148 & 24.6 & 33 & 21.6 & 114 & 26.0 \\
148 & 24.6 & 53 & 34.6 & 92 & 21.0 \\
7 & 1.2 & 0 & 0.0 & 7 & 1.6
\end{array}
$$

Share of patients with low disposable income (20-59 yrs.)

$\begin{array}{lllllll}\leq 18.2 \% & 149 & 24.8 & 31 & 20.3 & 115 & 26.2 \\ 18.3-21.9 \% & 148 & 24.6 & 33 & 21.6 & 114 & 26.0 \\ 22.0-26.6 \% & 150 & 25.0 & 50 & 32.7 & 97 & 22.1\end{array}$

Table 2 Characteristics of the participating 601 GPs

(Continued)

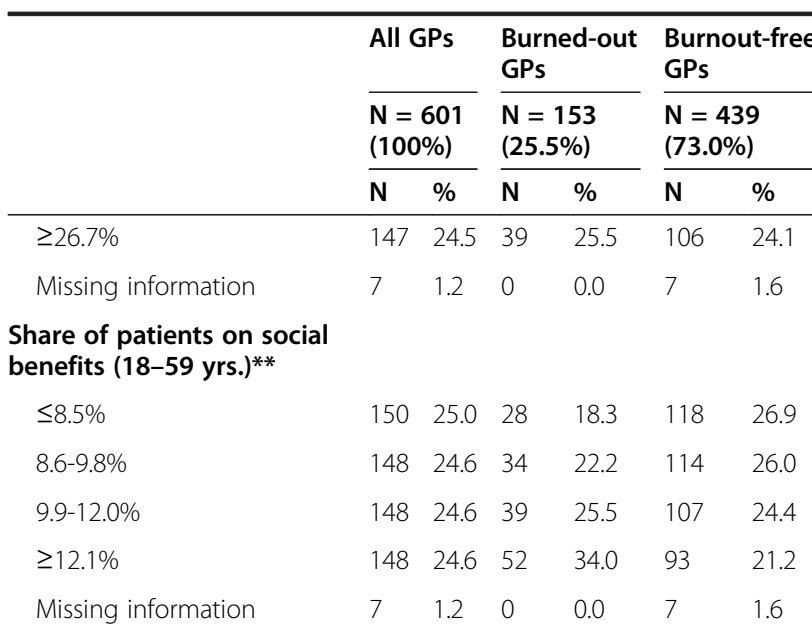

Share of children in families with low income $(<17 \mathrm{yrs}$.)

$\begin{array}{lllllll}\leq 6.2 \% & 150 & 25.0 & 35 & 22.9 & 111 & 25.3 \\ 6.3-8.7 \% & 149 & 24.8 & 30 & 19.6 & 117 & 26.7 \\ 8.8-11.9 \% & 148 & 24.6 & 41 & 26.8 & 106 & 24.1 \\ \geq 12.0 \% & 147 & 24.5 & 47 & 30.7 & 98 & 22.3 \\ \text { Missing information } & 7 & 1.2 & 0 & 0.0 & 7 & 1.6\end{array}$

Share of immigrants and descendants from non-western countries

$\begin{array}{lllllll}\leq 1.2 \% & 149 & 24.8 & 32 & 20.9 & 114 & 26.0 \\ 1.3-2.5 \% & 148 & 24.6 & 41 & 26.8 & 105 & 23.9 \\ 2.6-5.4 \% & 149 & 24.8 & 45 & 29.4 & 103 & 23.4 \\ \geq 5.5 \% & 148 & 24.6 & 35 & 22.9 & 110 & 25.1 \\ \text { Missing information } & 7 & 1.2 & 0 & 0.0 & 7 & 1.6\end{array}$

Share of patients living alone ( $\geq 30$ yrs.)

$\begin{array}{lllllll}\leq 21.6 \% & 150 & 25.0 & 27 & 17.6 & 119 & 27.1 \\ 21.7-24.4 \% & 148 & 24.6 & 43 & 28.1 & 103 & 23.5 \\ 24.5-28.6 \% & 149 & 24.8 & 45 & 29.4 & 104 & 23.7 \\ \geq 28.7 \% & 147 & 24.5 & 38 & 24.8 & 106 & 24.1 \\ \text { Missing information } & 7 & 1.2 & 0 & 0.0 & 7 & 1.6\end{array}$

Share of elderly patients with low disposable income ( $\geq 70 \mathrm{yrs}$.)

\begin{tabular}{lllllll}
$\leq 19.5 \%$ & 151 & 25.1 & 32 & 20.9 & 115 & 26.2 \\
$19.6-24.3 \%$ & 146 & 24.3 & 36 & 23.5 & 109 & 24.8 \\
$24.4-30.1 \%$ & 151 & 25.1 & 44 & 28.8 & 107 & 24.4 \\
$\geq 30.2 \%$ & 146 & 24.3 & 41 & 26.8 & 101 & 23.0 \\
Missing information & 7 & 1.2 & 0 & 0.0 & 7 & 1.6 \\
\hline
\end{tabular}

*Number of consultations per practice in 2011/number of GPs in the practice. **Excluding patients receiving study grants. 
Table 3 Summary of logistic regression analyses for variables associated with burnout $(\mathbf{N}=592)$

\begin{tabular}{|c|c|c|c|c|c|c|}
\hline & \multicolumn{3}{|c|}{ Unadjusted } & \multicolumn{3}{|c|}{ Adjusted model* } \\
\hline & OR & $95 \% \mathrm{Cl}$ & $p$-value & OR & $95 \% \mathrm{Cl}$ & p-value \\
\hline \multicolumn{7}{|l|}{ Sex of GPs } \\
\hline Males & 1.00 & & & 1.00 & & \\
\hline Females & 1.09 & $0.77-1.56$ & 0.623 & 0.99 & $0.68-1.45$ & 0.975 \\
\hline \multicolumn{7}{|l|}{ Age of GPs } \\
\hline $34-45$ & 1.00 & & & 1.00 & & \\
\hline $46-53$ & 1.04 & $0.62-1.76$ & 0.882 & 1.01 & $0.59-1.70$ & 0.984 \\
\hline $54-59$ & 0.95 & $0.56-1.61$ & 0.839 & 0.95 & $0.55-1.63$ & 0.856 \\
\hline $60-70$ & 0.73 & $0.41-1.28$ & 0.265 & 0.70 & $0.39-1.27$ & 0.247 \\
\hline \multicolumn{7}{|c|}{ Number of consultations in 2011} \\
\hline$\leq 4363$ & 1.00 & & & 1.00 & & \\
\hline $4364-5187$ & 0.91 & $0.52-1.58$ & 0.740 & 0.87 & $0.50-1.53$ & 0.634 \\
\hline $5188-6008$ & 0.94 & $0.56-1.59$ & 0.829 & 0.93 & $0.54-1.59$ & 0.790 \\
\hline$\geq 6009$ & 0.92 & $0.56-1.52$ & 0.741 & 0.90 & $0.54-1.51$ & 0.696 \\
\hline \multicolumn{7}{|l|}{ DADI } \\
\hline$\leq 21.5$ & 1.00 & & & 1.00 & & \\
\hline $21.6-25.5$ & 0.95 & $0.53-1.70$ & 0.851 & 0.98 & $0.53-1.81$ & 0.940 \\
\hline $25.6-30.0$ & 1.00 & $0.57-1.73$ & 0.986 & 1.07 & $0.59-1.94$ & 0.815 \\
\hline$\geq 30.1$ & 1.81 & $1.04-3.16$ & 0.037 & 1.91 & $1.06-3.44$ & 0.032 \\
\hline \multicolumn{7}{|c|}{ Share of unemployed patients ( $20-59$ yrs.) } \\
\hline$\leq 1.5 \%$ & 1.00 & & & 1.00 & & \\
\hline $1.6-1.9 \%$ & 1.62 & $0.92-2.84$ & 0.096 & 1.76 & $1.00-3.10$ & 0.051 \\
\hline $2.0-2.4 \%$ & 1.31 & $0.73-2.37$ & 0.371 & 1.49 & $0.79-2.82$ & 0.220 \\
\hline$\geq 2.5 \%$ & 1.82 & $1.03-3.22$ & 0.040 & 1.98 & $1.09-3.60$ & 0.026 \\
\hline \multicolumn{7}{|c|}{ Share of patients with education at high-school level or below (20-59 yrs.) } \\
\hline$\leq 22.6 \%$ & 1.00 & & & 1.00 & & \\
\hline $22.7-26.5 \%$ & 0.74 & $0.41-1.35$ & 0.330 & 0.79 & $0.41-1.50$ & 0.473 \\
\hline $26.6-29.8 \%$ & 0.84 & $0.48-1.50$ & 0.564 & 0.97 & $0.52-1.81$ & 0.921 \\
\hline$\geq 29.9 \%$ & 1.68 & $0.94-2.99$ & 0.077 & 1.93 & $1.00-3.71$ & 0.049 \\
\hline \multicolumn{7}{|c|}{ Share of patients with low disposable income (20-59 yrs.) } \\
\hline$\leq 18.2 \%$ & 1.00 & & & 1.00 & & \\
\hline $18.3-21.9 \%$ & 1.07 & $0.58-2.00$ & 0.822 & 1.08 & $0.58-2.02$ & 0.814 \\
\hline $22.0-26.6 \%$ & 1.91 & $1.11-3.33$ & 0.022 & 1.94 & $1.08-3.51$ & 0.027 \\
\hline$\geq 26.7 \%$ & 1.36 & $0.76-2.44$ & 0.293 & 1.35 & $0.75-2.43$ & 0.314 \\
\hline \multicolumn{7}{|c|}{ Share of patients on social benefits (18-59 yrs.) } \\
\hline$\leq 8.5 \%$ & 1.00 & & & 1.00 & & \\
\hline $8.6-9.8 \%$ & 1.26 & $0.67-2.35$ & 0.473 & 1.35 & $0.71-2.55$ & 0.362 \\
\hline $9.9-12.0 \%$ & 1.54 & $0.84-2.80$ & 0.161 & 1.69 & $0.91-3.13$ & 0.094 \\
\hline$\geq 12.1 \%$ & 2.36 & $1.34-4.14$ & 0.003 & 2.62 & $1.45-4.71$ & 0.001 \\
\hline \multicolumn{7}{|c|}{ Share of children in families with low income ( $<17$ yrs.) } \\
\hline$\leq 6.2 \%$ & 1.00 & & & 1.00 & & \\
\hline $6.3-8.7 \%$ & 0.81 & $0.44-1.49$ & 0.502 & 0.91 & $0.48-1.74$ & 0.776 \\
\hline $8.8-11.9 \%$ & 1.23 & $0.68-2.20$ & 0.494 & 1.40 & $0.75-2.61$ & 0.295 \\
\hline$\geq 12.0 \%$ & 1.52 & $0.86-2.70$ & 0.151 & 1.73 & $0.93-3.22$ & 0.082 \\
\hline
\end{tabular}


Table 3 Summary of logistic regression analyses for variables associated with burnout $(\mathbf{N}=\mathbf{5 9 2})$ (Continued)

\begin{tabular}{|c|c|c|c|c|c|c|}
\hline & \multicolumn{3}{|c|}{ Unadjusted } & \multicolumn{3}{|c|}{ Adjusted model* } \\
\hline & OR & $95 \% \mathrm{Cl}$ & p-value & OR & $95 \% \mathrm{Cl}$ & p-value \\
\hline \multicolumn{7}{|c|}{ Share of immigrants and descendants from non-western countries } \\
\hline$\leq 1.2 \%$ & 1.00 & & & 1.00 & & \\
\hline $1.3-2.5 \%$ & 1.39 & $0.77-2.52$ & 0.276 & 1.42 & $0.77-2.63$ & 0.261 \\
\hline $2.6-5.4 \%$ & 1.56 & $0.85-2.85$ & 0.153 & 1.57 & $0.84-2.92$ & 0.159 \\
\hline$\geq 5.5 \%$ & 1.13 & $0.62-2.08$ & 0.686 & 1.13 & $0.60-2.13$ & 0.697 \\
\hline \multicolumn{7}{|c|}{ Share of patients living alone ( $\geq 30$ yrs.) } \\
\hline$\leq 21.6 \%$ & 1.00 & & & 1.00 & & \\
\hline $21.7-24.4 \%$ & 1.84 & $1.01-3.35$ & 0.046 & 1.91 & $1.02-3.58$ & 0.043 \\
\hline $24.5-28.6 \%$ & 1.91 & $1.08-3.37$ & 0.026 & 1.98 & $1.08-3.66$ & 0.028 \\
\hline$\geq 28.7 \%$ & 1.58 & $0.88-2.83$ & 0.125 & 1.64 & $0.90-3.00$ & 0.108 \\
\hline \multicolumn{7}{|c|}{ Share of elderly patients with low disposable income ( $\geq 70 \mathrm{yrs}$.) } \\
\hline$\leq 19.5 \%$ & 1.00 & & & 1.00 & & \\
\hline $19.6-24.3 \%$ & 1.19 & $0.65-2.16$ & 0.575 & 1.25 & $0.67-2.35$ & 0.483 \\
\hline $24.4-30.1 \%$ & 1.48 & $0.86-2.55$ & 0.159 & 1.59 & $0.90-2.81$ & 0.112 \\
\hline$\geq 30.2 \%$ & 1.46 & $0.81-2.63$ & 0.208 & 1.52 & $0.81-2.85$ & 0.188 \\
\hline
\end{tabular}

*Adjusted for sex, age and number of consultations and GPs working within the same practice.

detailed information on the entire patient population in Central Denmark Region. Due to the list-system we knew precisely who were listed with a particular practice at what time. By using this information, a precise socio-economic profile for each practice could be estimated not relying on postcode-based or other neighbourhood-related deprivation measures.

One limitation of the study is that in group practices where GPs share the patient list, it cannot be determined whether all GPs were exposed to the same population. Based on the personal characteristics of the GPs, deprived patients may ask for the GP whom they prefer [21]. However, when repeating the analyses including only solo GPs, the pattern of results was replicated.

The high response rate was prominent taking into account the comprehensive and personal questionnaire. Still, $28 \%$ of the invited GPs did not participate. As we do not know whether it was the most or the least burdened GPs who declined to participate, the drop-out may have underestimated as well as overestimated the amount of burnout. Finally, although it has been argued that the MBI subscale scores should be treated as continuous data [17], we applied a categorical approach inspired by previous studies $[9,10,22-24]$. This could mean that details in the association have been lost, but this should not influence the direction of association and the conclusion. Although burnout is probably expressed along a continuum, the use of normative population-based cut-off scores for caseness of burnout gives an indication of the clinical significance of the findings.

\section{Comparison with existing literature}

Two former studies conducted in the UK revealed evidence of an association between patient deprivation and GP wellbeing [3,4] whereas another UK study did not provide such evidence [25]. The mixed results may be explained by the use of different measures of GP wellbeing as well as deprivation. One of the studies [4] used the Carstairs deprivation score [26] which emphasizes material deprivation (e.g. lack of car ownership and overcrowding). Two studies used the GPs' postal codes $[3,25]$ whereas one study used the patients' postal codes [4] for the measurement of deprivation.

A number of factors may explain the associations between patient deprivation and GP burnout. First, deprived patients and especially patients on social benefits have higher levels of multimorbidity and, in comparison to more affluent patients; their quality of life appears to be more negatively affected by the multimorbidity [27,28]. Therefore, GPs with a high share of deprived patients often have to deal with complex health issues, which may increase work pressure. Second, it is a well-known phenomenon that doctors are often recruited from the middle and upper social classes [29]. This can influence the doctor-patient-relation as many diseases have a social gradient affecting first and foremost patients with low socioeconomic position and differences in social class have been shown to be implicated in difficulties of communication [30]. Insofar troublesome communication is more frequent during encounters with deprived patients, this may explain why GPs in 
deprived areas are more inclined to become burned-out from their work.

Working in a deprived area may be a matter of selfselection with high patient-centred GPs being attracted by the challenges associated with taking care of socially deprived patients. Meanwhile, GPs with a high patientcentred orientation have been shown to find their job more stressful than less patient-centred GPs [31], perhaps as a result of 'compassion fatigue' [32]. Thus, the commitment which initially could motivate certain GPs to work in deprived areas might have a boomerang effect. Other self-selection mechanisms may be seen in relation to socio-economic aspects exemplified by our finding that the prevalence of burnout was lower the higher the proportion of non-western immigrants.

A high share of patients above 30 years of age living alone was associated with increased risk of burnout. Literature has consistently identified that unmarried individuals report poorer health and have a higher mortality risk than their married counterparts [33]. Even though the mechanisms responsible for the association between marital status and health are uncovered, the association may explain why GPs with a high share of patients living alone were more burdened by their work.

\section{Use of a multiple index of deprivation}

The main reason for using an index instead of socioeconomic indicators individually is that the indicators are expected to make a broad picture of the different aspects of having a patient population that can produce increased work pressure. However, not all variables have the same impact and we used data weighting inspired by the Jarman Index [19] which was based on GPs' opinion. According to critics, this approach was problematic since the GPs could only assess the burden on the basis of the patients they were exposed to [8]. A high share of immigrants is traditionally given a high weight, but in the present study, the share of immigrants was not significantly associated with burnout in the total GP population. This suggests that the deriving of weights has to be reconsidered. Even though deprivation indexes may have been developed for the purpose of measuring patients' needs, the results of this study suggest that the indexes may also be measures of GP workload. Financial incentives directed at GPs with a high score on the deprivation index would make it possible for them to reach the same income target with a shorter list of patients and may be part of the solution when attempting to reduce the increased burnout risk [8]. Other incentives which may be of great importance could be supervision and continuing medical education as also suggested by the results of a former study [34].
The finding that the share of patients on social benefits was more strongly associated with GP burnout than the DADI raises the question about whether a single factor would be a better predictor of workload than composite indexes. However, the denominator for this specific factor was the 18- to 59-year old patients and did not include children and elderly people who are the main users of health services. This study provided insight into the associations with specific variables and thus makes it possible to derive new weights for an index.

\section{Conclusions}

This study revealed a higher prevalence of burnout in GPs with a high share of deprived patients on their list compared to GPs with a low share of deprived patients. The single factor most strongly related to burnout was the share of patients on social benefits. The findings indicate that beside lower supply of GPs in deprived areas, people in these areas may also be served by GPs who are in a condition where they do not perform optimally. The findings of the present study call for intervention in order to overcome the inverse care law and to protect the mental health of GPs working in deprived areas. It would be highly relevant to examine whether supervision, continuing medical education, increased GP:patient ratios and remuneration incentives could reduce the increased risk of burnout associated with high exposure to deprived patients.

\section{Abbreviations}

Cl: Confidence interval; DADI: The Danish deprivation index; GP: General practitioner; OR: Odds ratio.

\section{Competing interests}

Funding: Centre for Cancer Diagnosis in Primary care is funded by the Novo Nordisk Foundation and the Danish Cancer Society. The project was further supported financially by the Committee of Quality and Supplementary Training (KEU) in Central Denmark Region.

The authors declare that they have no financial or non-financial competing interests.

The study is conducted in accordance with ethical guidelines. According to Danish law, questionnaire surveys do not require an ethical approval.

\section{Authors' contributions}

AFP participated in the design of the study, performed the statistical analyses and drafted the manuscript. PV participated in the design of the study, coordinated the obtaining of the Danish deprivation index and helped to draft the manuscript. Both authors read and approved the final manuscript.

\section{Acknowledgements}

We thank Christina Maar Andersen for her help during data collection and Kaare Rud Flarup for obtaining information for calculation of the Danish deprivation index. Moreover, we thank the Committee of Quality and Supplementary Training (KEU) in Central Denmark Region for their financial support of the project.

Received: 25 July 2014 Accepted: 29 November 2014 


\section{References}

1. Hart JT: The inverse care law. Lancet 1971, 1(7696):405-412

2. Watt G: The inverse care law today. Lancet 2002, 360(9328):252-254.

3. Mercer SW, Watt GC: The inverse care law: clinical primary care encounters in deprived and affluent areas of Scotland. Ann Fam Med 2007, 5(6):503-510.

4. Stirling AM, Wilson P, McConnachie A: Deprivation, psychological distress, and consultation length in general practice. Br J Gen Pract 2001, 51(467):456-460

5. Torjesen I: Analysis shows "postcode lottery" in access to GPs in England. BMJ 2014, 348:g3688

6. Campbell SM, Hann M, Hacker J, Burns C, Oliver D, Thapar A, Mead N, Safran DG, Roland MO: Identifying predictors of high quality care in English general practice: observational study. BMJ 2001, 323(7316):784-787.

7. Carlisle R, Avery AJ, Marsh P: Primary care teams work harder in deprived areas. J Public Health Med 2002, 24(1):43-48.

8. Carr-Hill RA, Sheldon T: Designing a deprivation payment for general practitioners: the UPA(8) wonderland. BMJ 1991, 302(6773):393-396.

9. Soler JK, Yaman H, Esteva M, Dobbs F, Asenova RS, Katic M, Ozvacic Z, Desgranges JP, Moreau A, Lionis C, Kotanyi P, Carelli F, Nowak PR, de Aguiar Sa Azeredo Z, Marklund E, Churchill D, Ungan M, European General Practice Research Network Burnout Study Group: Burnout in European family doctors: the EGPRN study. Fam Pract 2008, 25(4):245-265.

10. Arigoni F, Bovier PA, Sappino AP: Trend of burnout among Swiss doctors. Swiss Med Wkly 2010, 140:w13070.

11. Maslach C, Schaufeli WB, Leiter MP: Job burnout. Annu Rev Psychol 2001 52:397-422.

12. Shanafelt TD, Bradley KA, Wipf JE, Back AL: Burnout and self-reported patient care in an internal medicine residency program. Ann Intern Med 2002, 136(5):358-367.

13. Shanafelt TD, Balch CM, Bechamps G, Russell T, Dyrbye L, Satele D, Collicott P, Novotny PJ, Sloan J, Freischlag J: Burnout and medical errors among American surgeons. Ann Surg 2010, 251(6):995-1000.

14. Williams ES, Manwell LB, Konrad TR, Linzer M: The relationship of organizational culture, stress, satisfaction, and burnout with physician-reported error and suboptimal patient care: results from the MEMO study. Health Care Manage Rev 2007, 32(3):203-212.

15. Brazeau CM, Schroeder R, Rovi S, Boyd L: Relationships between medical student burnout, empathy, and professionalism climate. Acad Med 2010 85(10 Suppl):S33-S36.

16. Dyrbye LN, Massie FS Jr, Eacker A, Harper W, Power D, Durning SJ, Thomas MR, Moutier C, Satele D, Sloan J, Shanafelt TD: Relationship between burnout and professional conduct and attitudes among US medical students. JAMA 2010, 304(11):1173-1180.

17. Maslach C, Jackson SE, Leiter MP: Maslach Burnout Inventory Manual (3rd). Palo Alto, CA: Consulting Psychologists Press, Inc; 1996.

18. Vedsted P, Olesen F, Hollnagel H, Bro F, Kamper-Jørgensen F: Almen lægepraksis i Danmark. København: Månedsskrift for Praktisk Lægegerning; 2005 .

19. Jarman B: Underprivileged areas: validation and distribution of scores. Br Med J (Clin Res Ed) 1984, 289(6458):1587-1592.

20. Atkinson AB, Rainwater $L$, Smeeding TM: Income distribution in OECD countries. OECD Social Policy Studies 1995: 18

21. Stevenson AD, Phillips CB, Anderson $\mathrm{KJ}$ : Resilience among doctors who work in challenging areas: a qualitative study. Br J Gen Pract 2011, 61(588):e404-e410

22. Prins JT, Hoekstra-Weebers JE, Gazendam-Donofrio SM, Dillingh GS, Bakker AB, Huisman M, Jacobs B, van der Heijden FM: Burnout and engagement among resident doctors in the Netherlands: a national study. Med Educ 2010, 44(3):236-247

23. Houkes I, Winants $Y$, Twellaar M, Verdonk P: Development of burnout over time and the causal order of the three dimensions of burnout among male and female GPs. A three-wave panel study. BMC Public Health 2011, 11:240. 2458-11-240.

24. Ripp J, Babyatsky M, Fallar R, Bazari H, Bellini L, Kapadia C, Katz JT, Pecker M, Korenstein D: The incidence and predictors of job burnout in first-year internal medicine residents: a five-institution study. Acad Med 2011, 86(10):1304-1310.

25. Grieve S: Measuring morale-does practice area deprivation affect doctors' well-being? Br J Gen Pract 1997, 47(422):547-552.
26. Carstairs V, Morris R: Deprivation: explaining differences in mortality between Scotland and England and Wales. BMJ 1989, 299(6704):886-889.

27. Lawson KD, Mercer SW, Wyke S, Grieve E, Guthrie B, Watt GC, Fenwick EA: Double trouble: the impact of multimorbidity and deprivation on preference-weighted health related quality of life a cross sectional analysis of the Scottish Health Survey. Int J Equity Health 2013, 12(1):67. $-9276-12-67$

28. Salisbury C, Johnson L, Purdy S, Valderas JM, Montgomery AA: Epidemiology and impact of multimorbidity in primary care: a retrospective cohort study. Br J Gen Pract 2011, 61(582):e12-e21.

29. Pedersen $P$, Risor $T$, Eriksen TR, Petersson $B H$ : The social recruitment of medical students at Copenhagen University 1992/1993. Ugeskr Laeger 1994, 156(49):7372-7376.

30. Magnus SA, Mick SS: Medical schools, affirmative action, and the neglected role of social class. Am J Public Health 2000, 90(8):1197-1201.

31. Howie JG, Hopton JL, Heaney DJ, Porter AM: Attitudes to medical care, the organization of work, and stress among general practitioners. $\mathrm{Br} J \mathrm{Gen}$ Pract 1992, 42(358):181-185.

32. Zenasni F, Boujut E, Woerner A, Sultan S: Burnout and empathy in primary care: three hypotheses. Br J Gen Pract 2012, 62(600):346-347.

33. Robards J, Evandrou M, Falkingham J, Vlachantoni A: Marital status, health and mortality. Maturitas 2012, 73(4):295-299.

34. Brondt A, Sokolowski I, Olesen F, Vedsted P: Continuing medical education and burnout among Danish GPs. Br J Gen Pract 2008, 58(546):15-19.

doi:10.1186/s12939-014-0121-3

Cite this article as: Pedersen and Vedsted: Understanding the inverse care law: a register and survey-based study of patient deprivation and burnout in general practice. International Journal for Equity in Health 2014 13:121.

\section{Submit your next manuscript to BioMed Central and take full advantage of:}

- Convenient online submission

- Thorough peer review

- No space constraints or color figure charges

- Immediate publication on acceptance

- Inclusion in PubMed, CAS, Scopus and Google Scholar

- Research which is freely available for redistribution 